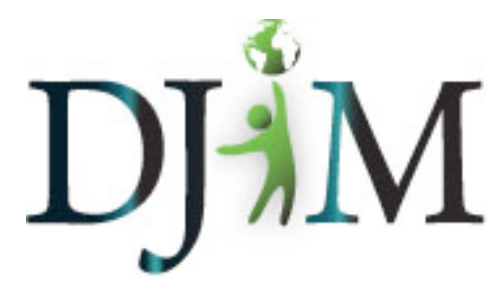

Volume 6 - Spring 2010 djim.management.dal.ca

\title{
"Two Roads to Middle Earth:" Comparing the Visualization of J. R. R. Tolkien's The Lord of the Rings and Peter Jackson's The Lord of the Rings Cinematic Trilogy
}

\section{Jennifer Grek Martin}

\begin{abstract}
When comparing a much-loved novel to a cinematic adaptation, many people will say, "the book was better." Even so, some of the same people remember scenes from the movie more vividly. Why? Building on Martin Barker's (2006) study of audience visualization, this paper examines Peter Jackson's film adaptation of J. R. R. Tolkien's The Lord of the Rings through DVD "making-of documentaries," and compares Jackson's cinematic vision with Tolkien's original work. The nature of film means adapting a textual work relies more on maintaining certain essential qualities of the original story, rather than a "page by page" rendering. Film may solidify a reader's visualization of these essential qualities by reinforcing similar images, or by forcing the reader to choose between their own images and those suggested in film adaptation.
\end{abstract}

\begin{abstract}
About the Author: Jennifer Grek Martin has an MSc in Geography and a BA in International Relations, both from the University of Wisconsin - Madison, and is currently seeking a MLIS degree at Dalhousie University. She has worked as an Archivist/Library technician at the Cataraqui Archaeological Research Foundation in Kingston, Ontario, and at the State Historical Society of Wisconsin. "Two Roads to Middle Earth" sprang from an essay written for Information and Society (INFO 5500), taught by Dr. Bertrum MacDonald in Fall 2009, as well as from genuine curiosity about why people always say "the book was better."
\end{abstract}




\section{Introduction}

"The book was better." How many times do we mutter similar statements as we walk out of movie theatres or turn off our DVD players? Martin Barker's (2006) research on visualization and the Lord of the Rings phenomenon, coupled with how people receive and retain information in the new digital "Information Age," provide valuable insight: why do some people privilege the book, while others more clearly remember the movie? I suspect a range of responses are possible, from rampant bibliophiles who always privilege the written word to cinema buffs who will never read the original work. People who adopt these two extremes, however, form their opinions out of principle. More interesting to me are those who both read the books and watch the movies and acknowledge an ability to visualize the work through both manifestations. To fully explore this concept, I will first consider the process of visualization for Peter Jackson's The Lord of the Rings through Barker's audience study and research on visualization. Building on this foundation, I will examine how Jackson's production team transformed prose into film, through "making-of documentaries" included in the Special Extended DVD editions of the film trilogy, and compare their cinematic interpretation with interpretations of J. R. R. Tolkien's original work. Finally, I will assess Jackson's interpretation based on how well the films communicate Tolkien's message, keeping in mind the technologies of film production and the information-receiving habits prevalent in the Information Age.

I first was introduced to Tolkien at the age of four, or was it five? It was so long ago that it is admittedly difficult to remember, though sitting on the floor listening to a 45rpm recording of The Hobbit while turning the pages of a brightly illustrated book is a memory I will never forget. I grew up with Arda, known by most as "Middle Earth," firmly in place in my mind. After many years of reading Tolkien's works, some characters and locations were very easy to picture, while others were more difficult. This did not inhibit my interaction with that world. My sentiments read very much like those expressed by one member of Barker's study audience:

I think you can always shut your eyes and see your own sort of place, but to see it in front of you, then you're getting the complete experience of it. I mean, there is [sic] some bits in the book that I can imagine more vividly than others, and you know there are some bits that actually you sort of almost skim by now,... (James, as cited in Barker, 2006, p. 1)

James, perhaps unknowingly, brings up a very important point: the ability to "shut your eyes and see your own sort of place." This ability is most often referred to as visualization. 
Barker's study of audience response to The Lord of the Rings film trilogy illuminates how the process of visualization can inform our understanding of how people receive, process, and interpret information. Drawing on theories surrounding the concept of mental imaging, Barker contends that mental imaging is natural, that it forms a part of "internal speech," that it is partial and incomplete, and that there is good reason to believe some people may produce more complete images than others (2006, p. 10). To temper the context of his study, Barker acknowledges that an established bias exists in academic circles privileging literary sources over visual adaptations, and admits that, for some, there may be little or no distinction between "seeing a film and visualizing its world" (2006, p. 12). However, unprovoked participant comments made during the study regarding visualization, via the book and via the films, were promising in making connections between visualization and the way people receive and process information.

The connection between mental imaging and theories regarding inner speech by Russian researchers Valentin Volosinov, Mikhail Bakhtin, and Lev Vygotsky forms the heart of Barker's argument. Inner speech is a way of thinking about human consciousness; in particular the relationship between consciousness and "dialogical," or socially-motivated, language (Barker, 2006, p. 13). Both inner speech and mental imagining are internal processes meant to relate the individual to the external world, and therefore Barker suggests mental imaging shares many properties of inner speech: it is achievement-oriented, it succeeds in unifying component parts, it is inseparable from the development of external competencies, it develops associations between the sense and meanings of words, and it is both spatially and chronologically situated (2006, pp. 13-14). Barker's findings support this connection. Responses from the audience substantiate visualization as a form of achievement. Viewers were able to distinguish between watching the film and envisioning the world that the film portrays. In addition, many viewers found confirmation when the film supported their visualizations, made comparisons between their mental images and those projected by the film, and overall felt a stronger sense of ownership of the story (Barker, 2006, pp. 18-9). Barker suggests that the visualization represented in viewer comments requires "higher order mental constructs" for one to effectively attach significance to the received information (2006, p. 19). Therefore, it is reasonable to conclude that imagining Middle Earth occurs when one reads The Lord of the Rings as well as when one watches the film adaptation, but how and why are they envisioned differently?

James, as stated above, admits: "there is [sic] some bits in the book that I can imagine more vividly than others" and the other "bits" he skims (as cited in Barker, 2006, p. 1). I contend that the ability to better visualize different aspects of a work is related to the reader's interest in that aspect. For example, I have never had difficulty imagining the people and places related to the Elves, because I find them particularly interesting. On 
the other hand, my friends and colleagues have expressed more interest in Tolkien's other cultures and characters. I have been told, "It's all about the Hobbits" (Dr. Anne Godlewska, personal communication, 2002), or, it is "all about" certain charactersAragorn, Frodo, or Sam being the key contenders. It stands to reason that we pay closer attention to those aspects of a book-places, people, objects, cultures-that interest us; therefore, visualizing those aspects comes more easily. These key aspects, however, make film adaptations more difficult. Not only does the film need to satisfy the general scope of a literary work in order to appear faithful (Barker, 2006), but it should not directly contradict readers' myriad specific visualizations for any given person, place, or thing (Martin, as cited in Barker, 2006, p. 7).

\section{Discussion}

The Lord of the Rings offers a brilliant palette for exploring the concept of visualization, as Tolkien not only draws upon different mythologies and languages, archetypal figures and cultures (Ford \& Reid, 2009, p. 71), but also describes landscape in almost excruciating detail. Landscape is one aspect that many can envision, though visualizations may vary depending upon where a person has been and what identity, if any, they ascribe to a particular landscape. It is no mystery that Tolkien wrote parts of The Lord of the Rings to reflect the English landscape; therefore, those people who recognize that connection and have particular affinity with that landscape will visualize and privilege a particular view:

...the Shire is very much Middle England, you know, shades of Derbyshire, but then I grew up there,... I was afraid, I think, I was afraid that some, this sound awful and I'm sorry, but that some American would get hold of the film you know, and then it would be all prairie land... even though it's New Zealand, one can identify quite strongly with the landscapes etcetera in the film. So, geographically, it was wonderful, the filmography was wonderful. (Stella, as cited in Barker, 2006, p. 2)

Tolkien's geography of Middle Earth is so complete that Karen Wynn Fonstad created An Atlas of Middle Earth (1991), tracing not only Frodo's journey in The Lord of the Rings, but spanning the breadth of Tolkien's works, including various battles, kingdoms, and voyages throughout the three Ages. Her regional and thematic maps complement the dedicated reader's vision of this world and provide yet another way to envision Middle Earth. Of course, Tolkien himself included maps within the published versions of his books, presumably with the understanding that the geographic scope of the works required visual reinforcement to be more fully understood.

Visual reinforcement is what many believe a film adaptation of a work provides. Actor Christopher Lee comments on differences between the book and the movie: "There are 
lots of things in these films, which are not in the books, and I think, in most cases, they are improvements, because they are scenes which have to be seen..." (as cited in Jackson, 2002). In Barker's study, one respondent commented after seeing the film adaptation:

I think it was different because I was able to visualise more of the things that Tolkien had described, and like the landscapes and things when I first read the book I didn't really know what...Tolkien was getting at but then after watching the movies I thought that ... I had a better idea of how Tolkien saw the things he'd written about which made it more interesting to read...because I can recognise parts of the books that were clearly in the film... (Fran, as cited in Barker, 2006, p. 2)

The most ardent bibliophiles might disagree with Fran. Sara Martin, on film representations of Emily Brontë's character Heathcliff, argues, "film adaptations almost inevitably cause problems for committed book-readers, because a film can embody characters too strongly," therefore causing conflict with a reader's own impressions (Martin, as cited in Barker, 2006, p. 7). I suggest that the struggle of reconciling the film's vision with the reader's own vision results in an even more concrete visualization. By actively engaging both visualizations and consciously defending or accepting one or the other, the characteristics of a visualization are more clearly imagined. This idea appears to be related somewhat to Barker's findings regarding shared imagining and comparison (2006, p. 19).

One of the obvious comparisons, especially with well-known and well-loved books like The Lord of the Rings, is how faithfully the movie represents the established written word. In other words, do audiences envision the same Middle Earth, and the same story, that is portrayed in the book? Again, the most ardent bibliophiles would consider any discrepancy from book to film to be important, but I will not include a list-and it would be a long one-of these discrepancies here. Instead, I emphasize that a film adaptation is not the book: adaptations are, in fact, different manifestations of an artistic work. To put text to film requires a significant change in medium; films are visual, aural, and, if one is discussing the full cinematic experience, highly situational. As such, a film cannot tell the story in the same way a novel can. Filmmakers like John Gilbert understand this point rather well: "literal adaptations [of a book] don't work. I think you've got to find what you think is essential to the book and make your movie of that" (as cited in Jackson, 2002). Peter Jackson adds: “... the book is a great book, the story is a great story, the characters are great, but it's unfilmable and it is unfilmable. If you were to just shoot the book, page by page, scene by scene, it would be a mess" (2002). Even Tolkien scholar Brian Sibley echoes this sentiment: 
Here you've got a book that's a thousand pages long; it encompasses a different geography, all kinds of races of beings and creatures. It's a book that took the author fifteen years to write. This is a challenging book to try to put on film. (as cited in Jackson, 2002)

The nature of film enriches visualization, as Philippa Boyens relates, "If you want to explain to the audience about the culture of the Dwarves, you cast John Rhys-Davies as the Dwarf and he'll tell you, he'll show you, he'll bring that culture to life for you" (as cited in Jackson, 2002). Accepting that a film cannot be shot "page by page" means that changes are inherent in the adaptation process. Therefore, understanding how Jackson's team adapted The Lord of the Rings gives valuable insight into how cinematic manifestations contribute to the visualization process and to the communication of information in general.

This stage of analysis focuses on how the film version of The Lord of the Rings was made, including both mechanical and conceptual aspects of production, and illuminates how the filmmakers fulfilled their own vision of Tolkien's epic tale. How am I able to do this? Not via "insider" connections, I assure you, but by the brilliant invention of the DVD. Not only was Jackson's The Lord of the Rings groundbreaking in special effects and digital rendering, but in considering the extended DVD edition of The Fellowship of the Ring, critics "... universally hailed it as setting a new benchmark in DVD releases of mainstream cinema" (Hight, 2005, p. 5). The first Appendix-there are two for each film in the trilogy-is entitled From Book to Vision and through a series of still photographs and short films, called by Hight "making-of documentaries" (2005, p. 6), one can retrace the steps Jackson and the entire production team took to adapt this challenging book to film. Again, the aim is not to pick apart the costumier's decision to make Arwen's riding coat blue, the aim is to analyze how the book The Lord of the Rings was envisioned by the filmmakers and whether they succeeded in creating a cinematic vision faithful to the essential quality Gilbert describes above.

Mechanically, the process of adapting Tolkien's book to film encompassed two main categories: converting Tolkien's prose to script and creating artistic renderings of actual camera shots-called, of course, "visualization." On the script side, Peter Jackson and Fran Walsh created the first rendition of a screenplay, based on the idea of two films. This script was subsequently altered once New Line Cinema approved a three-film adaptation, and Jackson and Walsh rewrote the script with the additional writer, Philippa Boyens (Jackson, 2002). Once the actors were cast, their contributions were taken into account and rewrites continued throughout filming on an almost daily basis. Actor John Rhys-Davies admits to possessing two large boxes full of rewrites, some with their envelopes "still unopened" (Davies, as cited in Jackson, 2002). On the "visualization" side, Christian Rivers "storyboarded" the film, or, in lay terms, he drew a small, cartoonlike image for every future camera shot- a process Jackson estimated took four to five 
years (2002). These images were videotaped and animated, preliminary shots taken and images re-sketched, and 3D computer animations developed-called "pre-vis"-for especially tricky angles and for scenes requiring integrated computer animations (Jackson, 2002). Changes that were made to either the script or visualization necessarily needed to be made to the other, and Jackson, who worked on both, was responsible for ensuring the image evoked from the words on the page somehow matched the image evoked from the images on the screen.

Conceptually, making the "unfilmable" book "filmable" required a certain amount of reworking of Tolkien's original story, but always with an eye to accuracy. Boyens commented that in order to turn "prose into filmic moments" any one aspect of the story needed to do more than one thing, and certain parts of the book had to be left out to keep the length of the film reasonable (as cited in Jackson, 2002). Sometimes, reworking meant making difficult choices. Jackson and Boyens describe choosing between dramatic tension and fidelity to the "untouchable" books (Boyens, as cited in Jackson, 2003a). One example was the choice to bring a host of Elves to Helm's Deep to aid the Rohirrim in their battle against the overwhelming force of Isengard. Boyens recalls "I have seen the film with audiences and every time those Elves show up, they cheer," even, she adds, when the die-hard Tolkienists know it is completely wrong, she contends at that moment they still feel something (Boyens, as cited in Jackson, 2003a). Why? Perhaps it is because the scene honours the "essential quality" of the book. Throughout Tolkien's The Lord of the Rings, it is clear that the Elves and Dwarves and all free peoples of Middle Earth are fighting their own battles against the forces of evil, and that alliances, both ancient and contemporary, are a central theme in Tolkien's writing (Valente, 2004). Tolkien may have not written that scene, but as actor Viggo Mortensen comments, "As long as you're carrying the spirit of the book with you, you can do a lot of things differently" (Mortensen, as cited in Jackson, 2004).

Commenting on the "spirit" of The Insider, the film adaptation of real-life events surrounding Jeffrey Wigand blowing the whistle on Big Tobacco (Brenner, 1996), Marie Brenner states, "In the movie [The Insider] the drama builds up to an emotional truth; it's unimportant to cross every "t" and dot every "i." ... it's [the movie] emotionally and philosophically accurate" (Brenner, as cited in Grossman, 1999, p. 62). Brenner's comments call into question the nature of accuracy. If filmmakers and scholars agree that a page by page shooting of The Lord of the Rings will not result in a watchable film, then accuracy, or fidelity to the written word, takes on a different meaning. Perhaps accurate visualizations of a film adaptation of a book have more to do with accessing the "essential quality" or "spirit" that comes through the prose. By focusing on the spirit, the fact that Tolkien never wrote that the Elves fought at Helm's Deep is no longer an inconsistency insofar as it remains faithful to deeper truths that Tolkien espoused. The 
fact that Boyens recalls the audience cheering at that point in the film means that the scene rings emotionally true.

Claire Valente explores how well the films "capture Tolkien's epic" (2004, p. 35). For the most part, Valente admires Jackson's ability to translate "the world of Middle Earth, nature and industrialization, fellowship and community, the role of the individual, and the centrality of mercy" (2004, p. 35). In our terminology, Valente believes these concepts can be well envisioned throughout Jackson's cinematic adaptations. Where Valente feels the films fail to live up to the spirit of the book is in their treatment of pre-modern and modern values, their devaluation of majesty and the role of higher powers, and their ambivalence toward victory (Valente, 2004). Here may be the crux of the difference between what some people envision through reading the book and envision via watching the film. Tolkien's Aragorn embodies a hidden majesty-"All that is gold does not glitter" (1991, p. 186)—but if that quality does not come across in the film, then the image of written Aragorn diverges from filmic Aragorn. In fact, Valente describes Jackson's Aragorn instead as "a reluctant hero" (2004, p. 38), while Ford and Reid contend that filmic Aragorn actually fears his lineage and, in not wanting to wield the sword Narsil, does not want to be king of Gondor (2009, p. 78). Another character, Faramir, suffered what some might consider character assassination. In the book he is Tolkien's most thoughtful and "eloquent spokesman for the conviction that the ends not only do not but cannot justify the means" (Valente, 2004, p. 40). In the book he rejects the power of the One Ring, but in the film he briefly succumbs to it (Jackson, 2003b). For those who strongly envision the character of Faramir as described by Tolkien, filmic Faramir rings a bit false. For Boyens, however, portraying Faramir as immune to the Ring would have been "death on film" (as cited in Jackson, 2003a).

So has Jackson failed? Does the film trilogy deviate so strongly from the source that envisioning the spirit of the book creates vastly different images than the spirit created by the films? Could this be why some privilege the book? Again, the answers are not so simple. Valente is right to point out that Tolkien wrote in a very different time than Jackson, who was "brought up in an age where hierarchy is suspect, truth relative, higher powers dismissed, and progress unquestioned" (2004, p. 38). Though I do not entirely agree with Valente's interpretation of modern views of progress, I certainly recognize that some of the values Tolkien emphasized might not resonate with modern audiences. Recalling the connection between inner speech and mental imaging that Barker makes, this facet is important to the concept of how people envision, particularly since, as mentioned above, visualization tends to be both spatially and chronologically situated. If Jackson had portrayed filmic Aragorn as the majestic Tolkien figure, it is entirely possible that modern audiences would not have responded positively toward the character. If Faramir had not succumbed to the power of the One Ring, the filmic power of the Ring would have been cut down in one stroke of an Elvish blade. 
It is hopefully clear from the above discussion that adapting a film not only means adapting across media-written words on a page to sound and images on a screenbut that it must be adapted across time as well. Different audiences, even those very familiar with Tolkien's works, may interpret his words differently depending on the culture or "time that is given" them (Tolkien, 1991, p. 64). Someone with little suspicion toward hierarchy might have no trouble envisioning a more majestic Aragorn, while another reading the same words may imagine one more akin to Jackson's version. Leaving aside bibliophiles who would privilege the book out of principle, I return to the original question: "why do some privilege the book, while others more clearly remember the movie?" We can safely say that, for some, the film simply does not correspond to the images they envision while reading the book and this situation depends, to some extent, on the interests of the person, whether the film accesses the spirit or essential qualities of the original book, and whether the age in which the film audience is living promotes those essential qualities. But this answers only part of the question. Why do some people seem to remember the movie?

For insight into this question we return to audience participant James, who stated in the above quotation: "... but to see it in front of you, then you're getting the complete experience of it," (as cited in Barker, 2006, p. 1). James probably had no idea he was contributing to the idea that mental imaging, as a type of internal speech, strives to unify component parts. Barker highlights this sense of "completeness" and "... the sense that "visualisation" helps viewers solve narrative puzzles" (2006, p. 3). Tolkien's The Lord of the Rings is over one thousand pages, not including the appendices, and contains a separate index for "Songs and Verses," "Persons, Beasts and Monsters," "Places," and "Things" (1991). The story is geographically and chronologically complex; some things happen after an event, if you are counting the pages, but actually happen before that event if you are following the storyline. Jackson admits the chronology was a problem, especially at the end of The Two Towers and throughout The Return of the King. Simplifying the order of events meant the storyline flowed more easily on film, but in the end, dramatic tension was sacrificed, as the audience already knew Frodo's fate, during the scene at the Black Gate, while the characters onscreen did not (Jackson, 2004). Marianne comments on the film's ability to simplify the story and foster a sense of completeness:

I read the description in the book and I just couldn't visualise it at all as soon as I saw how they visualised it in the film, it just sort of all fitted into place and it all made sense and the different bits of the story that happened there, sort of, I suddenly realised how it all fitted together, which I hadn't really done before ... the first two films lock the different bits like that sort of made the book fit in to place better ... (as cited in Barker, 2006, p. 2) 
The sense of completeness, of events making sense, combined with the visual nature of film is merely another way of communicating information. In combination with the written word, film has the power to strengthen certain "bits" of information so that they become part of a cohesive "whole," which speaks, again, to the higher order functions that Barker feels are integral to the process of envisioning. The process of visualization while one reads a book involves transforming words into a "sense" and to that sense is ascribed "meaning" (Barker, 2006). As reading is a very personal experience, the words, senses, and meanings are filtered through one's own interest, which as I mentioned above, is perhaps why some people envision certain things more clearly than others. On the other hand, seeing someone else's vision of a literary work in the form of a film adaptation not only inspires subsequent visualization, but it also has the capacity to invite comparison, solidify partial visualizations, and promote more complete understanding by retelling the story within the confines of cinematic tradition.

One of the confines of cinema is that the audience will only sit in a theatre for so long. The full text of The Lord of the Rings may take some people months to read, while, in the space of roughly nine hours, one can view the entire film trilogy and have a fairly comprehensive image of Tolkien's world and understanding of the main storyline. As mentioned previously, the age we live in affects the type of information we receive, and much has been written concerning societal movement into a post-industrial information age (Duff, 1998). To go a step further, one might say that we are in the Digital Information Age, as many, including Nicholas Carr, have commented on the effects of information overload, including a significant attention-span deficit made possible by digital media (2008). If people are becoming so used to instant information, then the choice between reading the book for months on end and watching the movie in an afternoon seems clear. Film adaptations, because of their multimedia nature, often offer more succinct, simplified, and complete versions of the stories told in novels. These features, as Barker suggests above, may allow people to form more complete mental images. People may more clearly remember the movie because it is presented in a manner that promotes stronger mental images and, in a society characterized by information overload, having stronger mental images increases the likelihood of information retention.

Another cinematic parameter is one that Jackson's trilogy has largely overcome-that of creating believable scenes with the help of computer animation. Apart from the usual "movie magic" employed to depict impossible or fantastical scenes, several techniques were developed during the filming of the trilogy, including digitally enhanced armies and the role of Andy Serkis, the actor behind the digitally created character Gollum (Jackson, 2003a, 2004). Not only was the structure of the book difficult to film, but to reiterate Sibley, "... it [the book] encompasses a different geography, all kinds of races of beings and creatures..." (as cited in Jackson, 2002). This becomes a challenge when 
one hopes to draw people into Middle Earth and help them envision the world more holistically. Finding geographically suitable places to film was a challenge, as well as interspersing real trees with mallern, pitting real people against trolls and Balrogs, and finding a way to visually depict disembodied evil (Jackson, 2004). These challenges to the process of visualization were not impossibilities due to the nature of digital forms of information. Indeed, half of this paper would not have been possible were it not for the Special Extended DVDs. People are interested in how films are made, and are willing to pay a bit extra for access to that information, especially for a much-loved work like The Lord of the Rings. Perhaps it is yet another form of Barker's "ownership" phenomenonsome people throw information overload to the wind and are willing to spend considerable time learning about how Jackson's team brought one of their most favourite works to life.

\section{Conclusion}

Did every scene in Jackson's trilogy correspond to the images I have imagined? Of course not, but that does not trouble me. Jackson was able to film The Lord of the Rings and to preserve the essential qualities of Tolkien's original work for a modern audience, and for that I am deeply grateful. The ability to bring a work to life has always been an admired quality of the film industry. For those people who envision in less-thancomplete ways, a film brings completeness. For those who are ardent bibliophiles, slight, or not-so-slight, changes from book to film solidify their own visualizations, either by reinforcing a similar image or by forcing the person to choose between their own image and the one invoked from the screen. Whether someone privileges the imagined world created by reading a book, or the imagined world brought about by images on the silver screen, is dependent upon these factors and on how well the filmmakers have captured the essential quality or "spirit" of the book. By doing so, they can make changes in accordance with the limitations of the filmic medium without changing how people envision the world behind the work-prose becomes "filmic moments". As evidenced throughout the "making-of documentaries," the difficulty of adapting The Lord of the Rings to film was tantamount to Frodo's journey to Mount Doom. Substantive changes are evident, especially to the characters Aragorn and Faramir, but necessary due to the nature of the filmic medium and to the difference in time and culture between Tolkien's writing and Jackson's filming. Considering the increased prevalence of images as conveyors of information in today's society, I suggest further study into the interrelationship between how people visualize information received from text and information received from images. I do not believe they are mutually exclusive and, indeed, serve as brilliant complements to one another. In the end, I believe Jackson succeeded because I believe Tolkien would have recognized his Middle Earth in 
Jackson's film trilogy. As Tom Shippey, author of Tolkien: Author of the Century said: "And now we have two roads to Middle Earth, two roads into the map-Tolkien as himself and Tolkien as interpreted by Jackson" (as cited in Jackson, 2004).

May the two roads go ever on and on... 


\section{References}

Barker, M. (2006). Envisaging 'visualisation': Some challenges from the international lord of the rings audience project. Film-Philosophy, (10)3, 1-25. Retrieved from http://search.ebscohost.com/login.aspx?direct=true \&db=f3h\&AN=24120637\&site=eh ost-live.

Brenner, M. (1996, May). The man who knew too much. Vanity Fair, 1-13. Retrieved from http://www.vanityfair.com/magazine/archive/1996/05/wigand199605.

Carr, N. (2008, July/August). Is Google making us stupid? The Atlantic Monthly, 301(6). Retrieved from http://www.theatlantic.com/doc/200807/google.

Duff, A. S. (1998). Daniel Bell's theory of the information society. Journal of Information Science, 24, 373-393. doi:10.1177/016555159802400601.

Fonstad, K. W. (1991). An atlas of middle earth. Boston: Houghton Mifflin Company.

Ford, J. A., \& Reid, R. A. (2009). Councils and kings: Aragorn's journey towards kingship in J. R. R. Tolkien's The lord of the rings and Peter Jackson's The lord of the rings. Tolkien Studies, (6), 71-90. Retrieved from http://muse.jhu.edu/login?uri=/journals/tolkien_studies/v006/6.ford.pdf.

Grossman, L. K. (1999). The insider: It's only a movie. Columbia Journalism Review, 60-62. Retrieved from http://search.ebscohost.com/login.aspx?direct=true\&db=f3h\&AN=BFLI01101099031 9885\&site=ehost-live.

Hight, C. (2005). Making-of documentaries on DVD: The lord of the rings trilogy and special editions. Velvet Light Trap: A Critical Journal of Film \& Television, (56), 4-17. Retrieved from http://search.ebscohost.com/login.aspx?direct=true \&db=f3h\&AN=19657073\&site=eh ost-live.

Jackson, P. (Director). (2002). From book to script. In The appendices part one: From book to vision, special extended DVD edition of The fellowship of the ring. [DVD]. New Line Home Entertainment, Inc.

Jackson, P. (Director). (2003a). From book to script. In The appendices part three: The journey continues, special extended DVD edition of The two towers. [DVD]. New Line Home Entertainment, Inc. 
Jackson, P. (Director). (2003b). The two towers. [DVD]. New Line Home Entertainment, Inc.

Jackson, P. (Director). (2004). From book to script. In The appendices part five: The war of the ring, special extended DVD edition of The return of the king. [DVD]. New Line Home Entertainment, Inc.

Tolkien, J. R. R. (1991). The lord of the rings. London: HarperCollinsPublishers.

Valente, C. (2004). Translating Tolkien's epic: Peter Jackson's Lord of the Rings. Intercollegiate Review, 40(1), 35-43. Retrieved from http://search.ebscohost.com/login.aspx?direct=true \&db=f3h\&AN=15206176\&site=eh ost-live. 